\title{
Sloveenia folkloristika ja etnoloogia I
}

\author{
Mare Kõiva, Andres Kuperjanov
}

\begin{abstract}
Teesid
Ülevaade tutvustab Sloveenia Teaduste Akadeemia (TA) eeskätt folkloristika ja etnoloogiaga seotud projekte, uurijaid ja institutsioone. Esitletakse TA Migratsiooni Instituudi uurimisteemasid ja trükiseid ning TA Etnoloogia Intituudi rahvajutuväljaandeid. Lähemalt vaadeldakse folklooriteoreetik Marija Stanoniku viimase aja kirjutisi ja projekte (kodukandi folkloori kogumine, piiblimotiivid rahvaluules, Saksa armees teeninud sloveeni sõdurite looming, teoreetilised käsitlused).
\end{abstract}

Märksõnad: etnoloogia, folkloristika, folklooriväljaanded, migratsioon, Sloveenia.

Paarinädalane töövisiit Sloveenia Teaduste Akadeemia Etnoloogia Instituuti viis meid kokku elava akadeemilise eluga Ljubljanas, mille muljeid tahame siinkohal jagada. Lisaks igapäevasele tööle arhiivis ja raamatukogus külastasime mitmeid uurimisteemalt lähedasi institutsioone, suhtlesime akadeemia külalistega Saksamaalt, Serbiast, Austraaliast, Horvaatiast. Kuulasime huvitavaid loenguid ning külastasime nende vanimate käsikirjade näitust ja kogesime kõikjal sooja kollegiaalsust.

Sloveenia Teaduste Akadeemia ja selle instituudid paiknevad Ljubljana südalinnas kobarana ümber päikselise väljaku. Samas asuv akadeemia asutuste poolt kirjastatud raamatute kauplus pakub esinduslikku ülevaadet originaaluurimustest, seeriatest ja tõlgetest, osutades elavale teaduselule. Erialakesksete väljaannete kõrval on interdistsiplinaarseid seeriaid, raamatud on kena disainiga, nagu muide kogu Teaduste Akadeemia atribuutika alates nimekaartidest, samuti talle kuuluvate hoonete sise- ja väliskujundus. Mitmete nutikate disainilahendustega on paljude uurimisasutuste hoonete ülimalt kõrged ja suured ruumid jaotatud privaatseteks heledates toonides kabinettideks, laboratooriumideks, raamatukogudeks.

Sloveenia Teaduste ja Kunsti Akadeemia on Sloveenia vanim teaduskeskus, mille eelkäijateks võib pidada 16. sajandi jesuiitide teoloogia ja filosoofia koole ning 1693. aastal Ljubljanas asutatud Academia Operosorumit. Praegu on akadeemial (lühend SASA) 74 täisliiget, 19 assotsieerunud liiget ning 84 korrespondentliiget välis-

http://haldjas.folklore.ee/tagused/nr26/sloveenia.pdf 


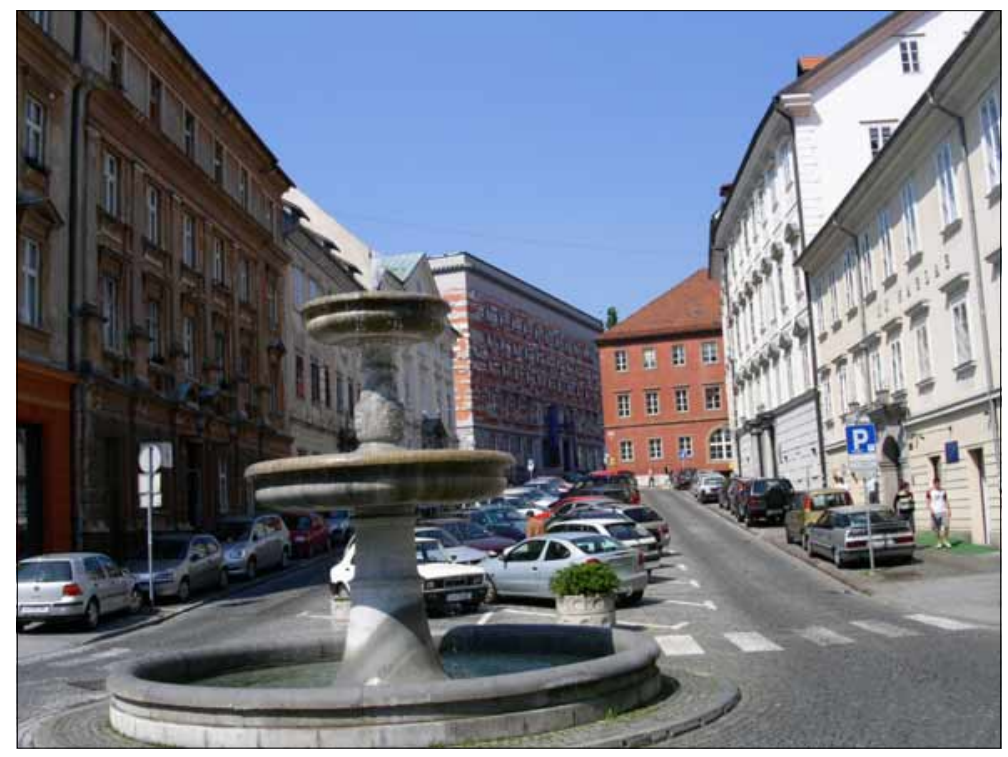

Foto 1. Väljak Novi trg Ljubljana kesklinnas. Kahel pool asuvad majad kuuluvad akadeemia asutustele, kõrge kandiline maja tagaplaanil on ülikooli raamatukogu. Andres Kuperjanovi foto 2004.

uurimisasutustest, kes osalevad kokku kuues sektsioonis. Akadeemiline maailm Novi trg väljakul külgneb monumentaalse raamatukoguhoone ja ülikooliga.

Mõningase kripeldusega tõdeme kohe alguses, et eesti ajakirjanduse jutt Sloveenia suurest interneti- ja arvutiseerumishüppest on tõsi. Arvutid on uued ja võimsad, varustatud korralike programmide ja suurte mugavate monitoridega. Elamuse pakuvad ka kohalikud raamatupoed oma üllatavalt mitmekülgse teaduskirjanduse valikuga. Sloveeni keeles ilmub humanitaar- ja sotsiaalteaduste vallas arvukalt väljaandeid ning ka võõrkeelse kirjanduse valik on avar.

Üks meie huvialuseid oli Emigratsiooni Instituut oma uurimisprogrammidega. Selle 9-liikmeline uurijaskond on orienteeritud interdistsiplinaarsusele. Osa projektidest on ühised muude Sloveenia akadeemiliste institutsioonidega nagu näiteks katusteema Perception of Slovenian Integration Policy, koostööprojekte on Skandinaavia ja Kesk-Euroopa riikidega. Keskuse uurimistemaati- 
ka on laiahaardeline, hõlmab 19. ja 20. sajandi migratsiooni, sloveeni diasporaa kultuuri ja identiteedi säilitamise problemaatikat, demograafilisi tendentse Jugoslaavias ja sellejärgses Sloveenias. Selliste teemadega seonduvalt hakkavad eelkõige silma uurimused sloveeni misjonäride tegevusest Aafrikas ja Ees-Aasias, endise Jugoslaavia riikide vahel toimuvast hilismigratsioonist, aga ka näiteks diasporaa kirjandusväljaannetest. Üsna loomulikult on vaatluse all ka Sloveeniasse tagasitulnute adapteerumine ja sellega seotud probleemid. Ühe suurema uurimisprojekti abil on registreeritud oma emigrantide arhiivid ja museaalid Prantsusmaal, Luxemburgis, Rootsis, Tšehhis ja Horvaatias. Instituut avaldab ingliskeelset infolehte, mis annab ülevaate jooksvatest uudistest, publikatsioonidest, konverentsidest. Lisaks koostatakse ajakirja Dve Domovini. Razprave o izseljenstvu: Two Homelands. Migration Studies, mille viimased numbrid on valdavalt ingliskeelsed. Sloveenikeelsetest artiklitest saab ülevaate pikemate võõrkeelsete kokkuvõtete abil. Eraldi ilmub veel monograafiate seeria Migracije.

Sloveene on miljoni jagu rohkem kui eestlasi, mistõttu meie keele-, identiteedi- ja kultuurihoiakud on lähedased, eriti arvestades viimaste sajandite kultuurimustrite sarnasust. Sloveenia on kuulunud Austria mõjusfääri, millele järgnes sotsialistlik Jugoslaavia-periood. Meie pikaajaline viibimine (balti)saksa kultuuriruumis ning kuulumine Nõukogude Liidu koosseisu võrreldava hulga aastate jooksul loob sarnasusi kuluuris ja hoiakutes. Mõlemal rahval on alanud teine postsotsialistlik kümnend. Siiski on sarnase kõrval erinevat, mis algab maastikust, külaarhitektuurist, rahvakunstist, majanduspiirkonnast ja päädib asjaoluga, et Tito-sotsialism ning kuulumine Mitteühinenud Rahvaste Organisatsiooni lubas sloveenidele suurema liikumisvabaduse, uurimistemaatika ja teaduskontaktid. Hämmastavalt sarnane on seevastu folkloor.

Teaduste Akadeemia Etnoloogia Instituudis töötavad koos nii folkloristid kui etnoloogid. Puhtalt folklooriteksti uurijaid on praeguses koosseisus vähem kui neid, kelle temaatika on seotud paikkondliku identiteedi, toitumiskultuuri, rituaalide, uuemate nähtustega ühiskonnas.

Üks folklooriteooriaga tegelejatest on Marija Stanonik, kelle viimaste aastate artiklid on käsitlenud mh folklorismi erinevaid vorme Sloveenias (vt nt Ell Vahtramäe tõlget VTK-raamatust aadressil http://www.folklore.ee/seminar/). 
ARUTELU

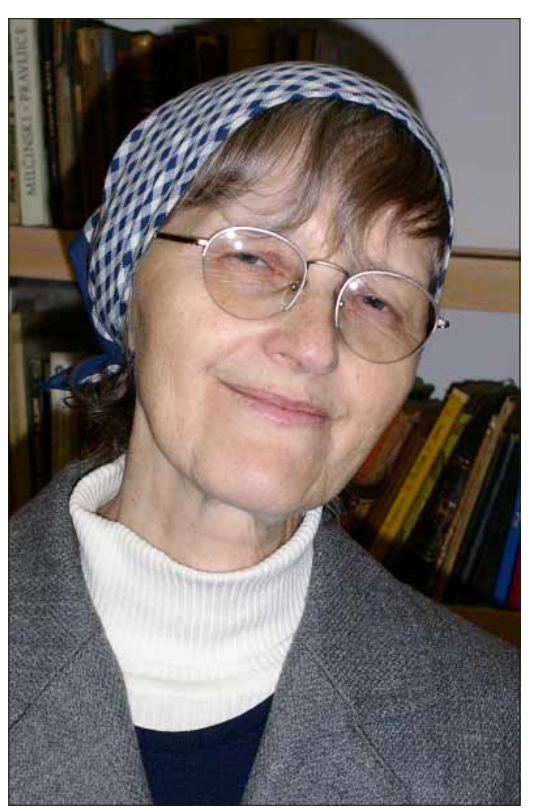

Mare Kõiva, Andres Kuperjanov

Foto 2. Marija Stanonik. Andres Kuperjanovi foto 2004.

Ettevalmistuselt ja huvidelt on ta teoreetik, enam kui kümne raamatu autor, suure osa oma tööajast on ta pühendanud ainesele, mida ta hindab uurimise põhitrendide äärealale kuuluvaks. Näiteks süvenemine oma koduküla seltsitegevusse ja lokaalsesse ajalukku ning pärimusse, millest on muu kõrval kasvanud välja kompleksne teemakäsitlus. Hiigelettevõtmine, peamiselt kohalike kooliõpetajate ja õpilaste võrgustiku abil folkloori kogumine, päädib hoolikalt süstematiseeritud käsikirjalise suurkoguga. Sellel on aga ka unikaalne väljund - 28 kaunilt kujundatud kõvakaanelist raamatut, koostatud kõigiti akadeemiliste nõuete kohaselt, valminud peatoimetaja Marija Stanoniku juhendamisel kohalikke autoreid kaasates. Eessõnad pärinevad keeleteadlastelt ja etnograafidelt. Väljaannete tekstid on esitatud murdekeeles foneetilisi erijooni säilitades. Arusaamise lihtsustamiseks on lisatud sõnastik ja registrid, nägusad kaardid, kust saab skemaatilise ülevaate nii piirkonnast enesest, kui selle asukohast Sloveenias.

2003. aastal ilmunud Nada Kerševani ja Marija Krebelj koostatud Düša na bicikli. Folklorne pripovedi iz Brkinov, doline Reke in okolice (Hing jalgrattal. Brkini mägede ja Reke oru ümbruse elanike folkloor) sisaldab üle 450 jutu. Raamatu on illustreerinud kohalik asjaarmastajast kunstnik. Klassikalise folkloori kõrval on kogumikku valitud ajaloost kõnelevaid pajatusi ja suulist ajalugu, jutte ebatavalistest sündmustest, lugusid pidutsemistest ja arstimistest. Valitu kajastab mõnevõrra piirkonna etnilisi ja usulisi minoriteete: õigeusklikke uskokke ja saksakeelseid kočevare. Eessõna annab ülevaate piirkonna ajaloo, kultuuri ja keele erijoontest, tüüpilistest elatusaladest ja pidustustest. Viimases raamatus on näha, kui 
suure osa Sloveeniast on trükised juba katnud. On tore, et viimaste raamatutega käib kaasas helikandja, mille vahendusel saab murdekeelt ja folklooripärimust paremini mõista, kuna nüüd on võimalik kuulda murdetekste ehedas esituses. Kogu projekti rahastamist on seni toetanud haridusministeerium.

Od setve do žetve (Külvist lõikuseni) kujutab endast sloveeni poeetilises folklooris leiduvate piiblimotiivide konkordantsi ja tõlgendust. Kaunilt kujundatud raamatus vaadeldakse Vana ja Uue Testamendiga seotud legendide, palvete ja uskumuste kajastusi rahvapärimuses. Raamatut elavdavad värvitahvlitel katked Sloveenia kirikutes leiduvatelt freskodelt ja altarimaalidelt, vanimad neist pärinevad 13. sajandist.

Interdistsiplinaarsele äärealale kuulub näiteks Teise maailmasõja ajal Saksa sõjaväes teeninud sloveeni noormeeste luuletuste valimik koos kommentaaride, biograafiate ja ajalooliste ülevaadetega. Erinevatesse Euroopa riikidesse pillutatud poisid on kirjutanud luuletusi kodumaale saadetud kirjadesse, tähendanud päevikutesse. Teemad on igavikulised: nostalgia armsate inimeste, kodu

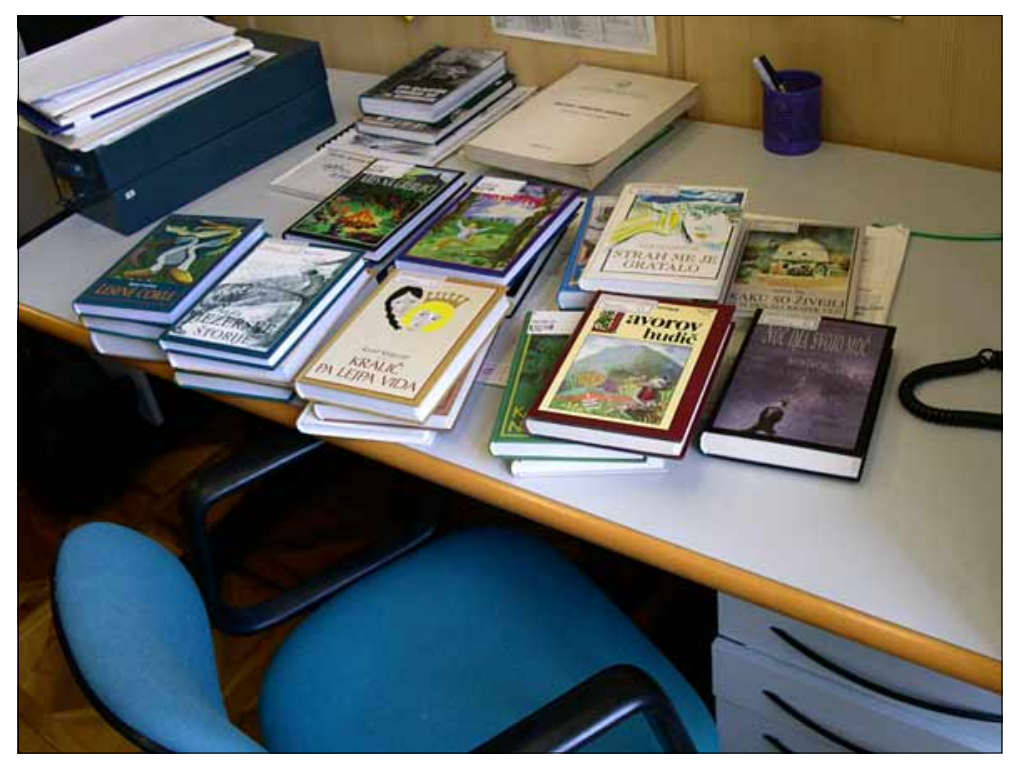

Foto 3. Lokaalset pärimust sisaldavad raamatud on kaunilt kujundatud. Andres Kuperjanovi foto 2004. 
ja isamaa järele, kuid ka luulepildid linnadest, milles ajutiselt asutakse, sh pildikesed Tallinnast. Selle ja teistegi raamatute valmimisega on sõlmunud kontaktid vastavate seltside ja ametialade esindajate ning kohaliku elu edendajatega. Folkloristi elu kulgeb harva kabinetivaikuses käsikirju uurides, pigem ikka seotuna inimeste, rühmade ja liikumistega.

2001. aastal ilmunud Teoretični oris slovenstvene folklore (Sloveeni kirjandusliku folkloori teoreetilised peajooned) tegeleb autori sõnutsi ühiskonnas leviva vastumeelsusega autentsete folkloori ilmingute vastu ja püüab oma uurimisvaldkonda objektiivselt hinnata. Raamatut iseloomustab üldlevinud idealiseeriva ja kommertsialiseerunud folklorismiga päädiva suhtumise vastandamine autentsele pärimusele, mis väljendub näiteks sloveeni ajakirjanduses ilmunud artiklite sageli negatiivses suhtumises. Enam kui 400-leheküljeline monograafia püüab hõlmata peaaegu kõiki folkloristika põhiprobleeme. Ühtlasi on esitatud võrdlevaid hinnanguid ameerika, skandinaavia, saksa, vene ja sloveeni vastavatele teooriatele. Näiteks korrastab ja liigitab autor folkloristika terminoloogiat, vaatleb folkloori suhteid erinevate naaberdistsipliinidega nagu keeleteadus ja eriti murdekeele uuringud, kirjandusteadus; eraldi tähelepanu all on folkloori erinevus triviaalkirjandusest. Folkloori käsitleb M. Stanonik siiski kirjanduse ühe haruna. Vaadeldakse termini folkloor juurdumist Sloveenias, sünonüümseid termineid ja nende kasutusvälju, samuti klassifikatsiooni teket. Terminite puhul esitatakse nende ajalooline areng ning $\mathrm{nn}$ standardiseeritud variandid, eristatakse alaterminid. Palju tähelepanu on pälvinud antonüümsus ja analoogia just kirjandusteadusega. Kesksed 20. sajandi terminid, nagu sünkretism, teatrielemendid, kontekst, välitööd, folkloori elustaadiumid, ja ka jäädvustamise ja editeerimisega seotud problemaatika esitatakse liigitatult ja koos põhjendustega. Monograafia lõpul esitab Marija Stanonik seitse kirjandusliku folklooriga seotud paradoksi. Viimane neist sedastab, et rahvaproosa on olemuselt personaalsem kui rahvapoeesia, vastupidiselt ilukirjandusele, kus poeesia on märgatavamalt isiklikum. Mahuka ingliskeelse kokkuvõttega raamat on kasulik lugemisvara igale teoreetiliste üldteemadega tegelejale. Teisalt on selle näol tegemist väljaandega, mille huvitavus seisneb mh ameerika ja vene folkloristikas käsitletud probleemide kõrvutamises ja osutuses, et paljud samaaegselt erinevatel mandritel toimunud otsingud olid lähenemisviisilt erinevad. 
Marija Stanonik on ka A4 formaadis ajakirja Slovenstvena folkloristika (ilmub Sloveenia Kongressi toetusel) toimetaja. Selle lühiartiklid on orienteeritud laiemale lugejaskonnale ja sisaldavad informatsiooni ning ülevaadete kõrval näiteks rubriike "Meie arhiividest", "Tudengikülg", "Intervjuu".

Eespool loetletud folklooriseeriad ei ole ainukesed, millega etnoloogiainstituudi folkloristid ja etnoloogid on seotud. Hoopis teise ülesehitusega on lastele mõeldud kõvakaaneline professionaalsete kunstnike illustreeritud arhiivitekstide põhine seeria Slovensko propovedi. Zbirka Zakladnica slovenskih propovedi (Sloveeni pärimus. Valik sloveeni pärimuse varamust). Needki on kommenteeritud ja sõnastikega varustatud raamatud, kuid eessõna piirdub umbkaudu 3-4 leheküljega. Ka on valimikes esitatu enamasti arhailisem jutupärimus, mida elavas pruugis enam ei kohta. Nimetame siinkohal Roberto Dapiti ja Monika Kropej valimikku Visoko v gorah, globoko v vodah (Kõrgel mägedes ja sügaval vee all), mis vahendab hiiglasepärimust, sest on ju enamik Sloveenia maalilisi maapinnavormegi just hiiglaste kätetöö või nende igapäevaelu märgid. Zmago Šmiteki koostatud Odkod je ta naš svet? (Kust on pärit meie maailm?) sisaldab loomis- ja tekkelugusid, Sledovi potujočih duš (Rahutute hingede jäljed) sisaldab kummitustega seotud pärimust, Monika Kropej V somraku kraljestva palčkov in škratov (Päkapikkude ja krattide kuningriigis) sisaldab jutte üleloomulikest olenditest.

Kas ühel populaarsete väljaannete seerial on teise ees eeliseid? Kindlasti seevõrra, et üks annab kaasaegsetele inimestele võimaluse näha trükituna lugusid, mida nad tänasel päeval mäletavad, mis räägivad neile tuntud inimestest ja sündmustest. Ühtaegu tähendab see kontrollkogumist, mis osutab folkloorinähtuste püsivusele ja taandumisele, aitab näha uute lugude tekkemehhanisme. See võimaldab kasutada enam murdekeelt, kuna piirdub kindla piirkonnaga. Teine seeria edastab temaatiliselt süstematiseeritud jutuvaramu paremiku ja toob lugejani vanu ja unustusse langenud mütoloogilisi motiive. Mõlemal suunal on kahtlemata oma auditoorium. Jääb üksnes soovida jõudu jätkamiseks.

Kui võrrelda Eestiga, siis meie rahvajuturaamatute kõrgaeg langeb 19. sajandisse ja 20. sajandi algusesse, kus stiilipaletilt eritasemelised kirjamehed ja päriskirjanikud, folkloristid nagu Matthias Johann Eisen koostasid valimikke ja temaatilisi rahvaraamatuid. Järgneval poolsajandil avaldati mitmeid akadeemilisi antoloogiaid 
ning valimikke. 20. sajandi viimasel veerandil läks rahvajuttude avaldamine eeskätt kirjanike ja kohalike entusiastide kätesse, kes, aimates mütoloogilise ainese ja suulise ajaloo nõudlust, kirjastasid muistendeid ja muid rahvajutte, neid osalt ümber jutustades ja töödeldes. Üsna selgesti nähtav on uusmütoloogia, kunstmuistendite ning -muinasjuttude loomise diskursus. Lugejad võtavad selliseid raamatuid vastu huvitunult ja innuga, olgu autoreiks Edgar Valter, Eno Raud, Henno Käo või teised kirjanikud ja kunstnikud. Folkloristid on omalt poolt sekundeerinud arhiivikirjapanekute avaldamisega. Seda eeskätt kohaliku lugeja paikkondlikku huvi silmas pidades. 